\title{
The Study for Transportation Planning Considered the Inventory Using Hybrid Genetic Algorithm
}

\author{
Shinichiro Ataka \\ Graduate School If information, \\ Production \& Systems, Waseda University \\ 2-7 Hibikino, Wakamatsu-ku, \\ Kitakyushu-shi, Fukuoka, Japan \\ ataka@fuji.waseda.jp
}

\author{
Mitsuo Gen \\ Graduate School If information, \\ Production \& Systems, Waseda University \\ 2-7 Hibikino, Wakamatsu-ku, \\ Kitakyushu-shi, Fukuoka, Japan \\ gen@waseda.jp
}

\begin{abstract}
The transportation planning (TP) is well-known basic network problem. However, for some real-world applications, it is often that the TP model is extended to satisfy other additional constraints or performed in several stages. In this study, we formulate the two-stage transportation planning with inventory and exclusionary side constraints (esc-2ITP). In this model, one week divided into some terms and the annual demands of delivery centers are satisfied for each them and it includes the additional constraint in which the simultaneous shipments between some plants are prohibited. To solve the problem, we propose the hybrid Genetic Algorithms (h-GA) approach by using a prioritybased encoding method.
\end{abstract}

\section{Categories and Subject Descriptors}

G.2.2 Mathematics of Computing, DISCRETE MATHEMATICS, Graph Theory, G.2.3 Mathematics of Computing, DISCRETE MATHEMATICS, Applications

\section{General Terms}

Algorithms, Design

\section{Keywords}

Transportation Planning, Inventory, Priority-based encoding, hybrid Genetic Algorithm.

\section{INTRODUCTION}

Transportation Planning (TP) is well-known basic network problem [1]. However, the concept of inventory is not included in a traditional TP models. Moreover, time concepts, such as a carrying cost in a certain period, are not included. Even if it is a plant that belongs to the same company, delivery methods may be different for each product.

Genetic Algorithm (GA) is solution search technique copied from evolution of a creature. It is applied to various fields since it was suggested, and application to TP is the one example, too. GA is a effective technique for a non-linear problems, it can support the problem that is impossible of a calculation by general LP software. But GA has some problems. These are high calculation load, precocious convergence to a limited part solution, complexity of parameter setting.

Copyright is held by the author/owner(s).

GECCO'08, July 12-16, 2008, Atlanta, Georgia, USA.

ACM 978-1-60558-130-9/08/07.
In this study, we formulate the two-stage transportation planning with inventory and exclusionary side constraints (esc-2ITP) [2]. In this model, a certain period divided into some terms and the annual demands of delivery centers are satisfied for each them. This model includes the additional constraint in which the simultaneous shipments between some plants are prohibited. To solve the problem, we apply the hybrid Genetic Algorithms (hGA) approach. Finally, numerical experiments with various scales of logistics network problems are used to show the effectiveness and the efficiency of our approach by comparing with the recent researches.

\section{MATHMATICAL FORMULATION}

Figure 1 is the sample model of esc-2ITP consisting of $I$ plants, $J$ DCs and $K$ customers.

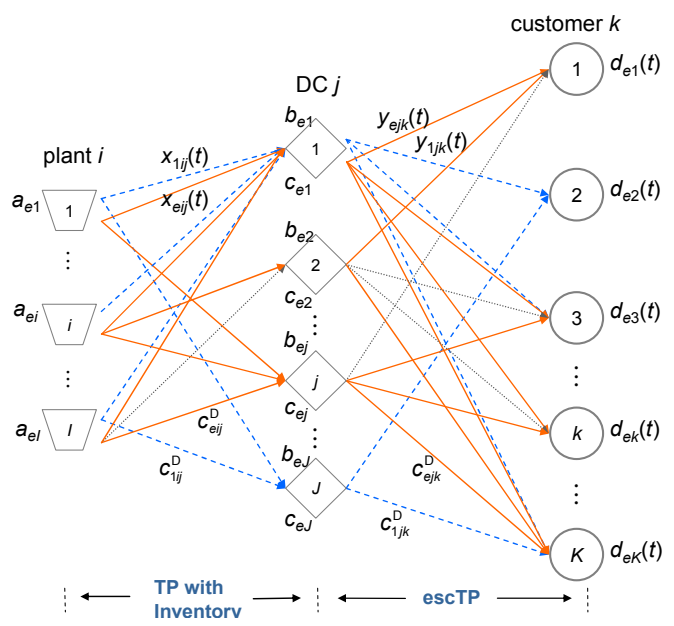

Figure 1. Sample of esc-2ITP

Index

$$
\begin{aligned}
& i: \text { plant, } i=1,2, \ldots, I \\
& k: \text { customer, } k=1,2, \cdots, K \\
& e: \text { product ID, } e=1,2, \cdots, E
\end{aligned}
$$

\section{Parameter}

$a_{e i}$ is capacity of plant $i$ for product $e . b_{e j}$ is capacity of DC $j$ for product $e . d_{e k}(t)$ is demands of customer $k$ for product $e$ in period $t . c_{e j}$ is carrying cost in $\mathrm{DC} j$ for product $e . c_{e i j}^{\mathrm{D}}$ : delivery cost for product $e$ from plant $i$ to $\mathrm{DC} j$ in period $t . c_{e j k}^{\mathrm{D}}$ is delivery cost for product $e$ from DC $j$ to customer $k$ in period $t . c_{e i}^{\mathrm{P}}$ : manufacture cost of product $e . p_{e i}(t)$ is quantity of production of 
plant $i$ in period $t . u_{e j}(t)$ is amount of inventories of the DC $j$ in period $t$

\section{Decision variable}

$x_{e i j}(t)$ is shipment amount of product $e$ from plant $i$ to DC $j$ in period $t . y_{e j k}(t)$ is shipment amount of product $e$ from DC $j$ to customerk in period $t$

The esc-2ITP considered by this research can be formulated as follows.

$$
\begin{array}{ll}
\min \quad z=\sum_{t=1}^{T} \sum_{e=1}^{E}\left(\sum_{i=1}^{I} \sum_{j=1}^{J} c_{e i j}^{\mathrm{D}} x_{e i j}(t)+\sum_{j=1}^{J} \sum_{k=1}^{K} c_{e j k}^{\mathrm{D}} y_{e j k}(t)+\sum_{i=1}^{I} c_{e i} u_{e i}(t)\right. \\
& \left.+\sum_{j=1}^{J} c_{e j} u_{e j}(t)+\sum_{i=1}^{I} c_{e i}^{\mathrm{P}} p_{e i}(t)\right) \\
\text { s. t. } \quad & u_{e j}(t)=u_{e j}(t-1)+\sum_{i=1}^{I} x_{e i j}(t)-\sum_{k=1}^{K} x_{e j k}(t), \forall e, j, k, t \\
& u_{e i}(t-1)+p_{e i}(t)<a_{e i}, \forall e, i, t \\
& u_{e j}(t-1)+\sum_{i=1}^{I} x_{e i j}(t) \leq b_{e j}, \forall e, i, j, t \\
& \sum_{e=1}^{E} \sum_{j=1}^{J} y_{e j k}(t) \geq d_{e k}(t), \quad \forall e, k, t \\
& y_{e j k}(t) y_{f j j}(t)=0, \quad(e, f) \in D_{l}, \quad \forall l, k, t \\
& x_{e i j}(t), y_{e j k}(t) \geq 0, \forall e, i, j, t
\end{array}
$$

The equation (1) is objective function for minimizing total cost. Constraint (2), (3) show the inventory of plant and DC. The constraint (4) represent capacity constraint of DCs. Constraint (5) is customer demands in period $t$. Constraint (6) represents the exclusionary side constraint. This shows that two different DC $j$ and $l$ are not allowed to serve the customer $k$ simultaneously.

\section{HYBRID GENETIC APPROACH}

In this study, we use priority-based encoding developed by Gen \& Cheng (2000). We adapt weight mapping crossover (WMX) and swap mutation is used. The roulette wheel selection performs selection.

In traditional GA, parameters are fixed and evolution process is followed based on the value. By this method, always crossover and mutation occur by same probability, and there is no diversity which must be in the evolution process. There must be probability for which it was suitable for every generation. If the probability is applicable to the generation, we can obtain better solution quality, also computation time will become short.

In this research, we apply the hybrid priority-based Genetic Algorithm (h-priGA) [1]. The fuzzy logic controller (flc) is built into hGA used by this study, and auto tuning of a parameter is performed to it by an evolution process.

\section{NUMERICAL EXPERIMENTS \& CONCLUSIONS}

We perform a comparison experiment between spanning tree based GA (st-GA) and priGA and h-priGA. Table 1 is the test data that we used for an experiment, and these data were generated randomly. The delivery cost generated from a uniform distribution between 20 and 35 . The rute that cannot use for delivery was made at $10 \%$ of the number of all nodes at random, and it was given a vast cost. In addition, the number of products set it to 2. The unit inventory cost of each product assumes it 2, 3 each. In addition, we divide one week into 4 periods and consider it. In a plant, the quantity of production of each period is performed in reference to previous period demand.

In this study, we decide the amount of production in current period from the following equation (Exponential smoothing).

$$
y_{e j k}^{\mathrm{F}}(t)=\alpha y_{e j k}(t-1)+(1-\alpha) y_{e j k}^{\mathrm{F}}(t-1)
$$

Here, $y_{e j k}^{\mathrm{F}}(t)$ is the amount of demand forecasting in period $t$. The value which deducted the present volume of inventories from $y_{e j k}^{\mathrm{F}}(t)$ serves as each order quantity of DC. Table 2 gives best, average, average, standard deviation and average computation time (ACT) of 30 runs.

Table 1. Problem data

\begin{tabular}{c|c|c|c|c|c}
\hline $\begin{array}{l}\text { Problem } \\
\text { No. }\end{array}$ & $\begin{array}{l}\text { No. of } \\
\text { Plants }(i)\end{array}$ & $\begin{array}{l}\text { No. of } \\
\text { DCs }(j)\end{array}$ & $\begin{array}{l}\text { No. of } \\
\text { customers }(k)\end{array}$ & $\begin{array}{l}\text { Population } \\
\text { size }\end{array}$ & $\begin{array}{l}\text { Max } \\
\text { generation }\end{array}$ \\
\hline 1 & 3 & 4 & 5 & 100 & 1000 \\
\hline 2 & 3 & 6 & 10 & 100 & 1000 \\
\hline 3 & 4 & 8 & 15 & 100 & 1000 \\
\hline 4 & 4 & 10 & 30 & 100 & 1000 \\
\hline
\end{tabular}

From numerical experiments, the validity of h-priGA was shown especially in computation time. However, today's distribution channel becomes a flexible form. The flexible of the model that I suggested this time, consideration of more concrete inventory control technique or the shortness of product life cycle like these days is a future problem.

\begin{tabular}{|c|c|c|c|c|c|c|c|c|c|c|c|c|c|}
\hline \multirow[b]{2}{*}{$\begin{array}{c}\text { Problem } \\
\text { No. }\end{array}$} & \multirow[b]{2}{*}{$P_{\mathrm{C},} P_{\mathrm{M}}$} & \multicolumn{4}{|c|}{ st-GA } & \multicolumn{4}{|c|}{ priGA } & \multicolumn{4}{|c|}{ h-priGA } \\
\hline & & Best & AVG & SD & $\mathrm{ACT}(\mathrm{s})$ & Best & AVG & SD & $\mathrm{ACT}(\mathrm{s})$ & Best & AVG & SD & $\mathrm{ACT}(\mathrm{s})$ \\
\hline 1 & $0.3,0.1$ & 44354.00 & 44433.87 & 873.80 & 4.29 & 44250.00 & 44419.80 & 71.33 & 4.07 & 39219.21 & 40277.17 & 47.38 & 2.90 \\
\hline 2 & $0.5,0.3$ & 49281.41 & 50835.80 & 868.07 & 9.27 & 46122.13 & 488118.2 & 1079.26 & 7.79 & 44783.00 & 46200.70 & 775.12 & 3.27 \\
\hline 3 & $0.7,0.3$ & 45107.00 & 47471.20 & 1403.79 & 15.49 & 41483.16 & 43405.44 & 1375.61 & 12.00 & 40336.85 & 41389.23 & 583.36 & 3.83 \\
\hline 4 & $0.7,0.1$ & 40599.10 & 42097.87 & 921.69 & 19.89 & 39223.00 & 40495.23 & 855.40 & 14.39 & 37039.03 & 37817.20 & 411.51 & 6.24 \\
\hline
\end{tabular}

\section{REFERENCES}

[1] M. Gen, R. W. Cheng and L. Lin, "Network Models and Optimization: Multiobjective Genetic Algorithm Approach", Springer, In Press, 2008.

[2] M. Sun, "The transportation problem with exclusionary side constraints and two branch-and-bound algorithms", European Journal of Operational Research, vol. 140, no. 3,

Table 2. Comparison result

pp. $629-647,2002$ 